\title{
Sociologia no Ensino Médio: institucionalização da disciplina e produção científica sobre o tema
}

\author{
Sociology in High School: institutionalization of the discipline and \\ scientific results about the topic
}

\section{La Sociología en la Secundaria: institucionalización y producción científica sobre el tema}

\author{
KELEN CHRISTINA LEITE* \\ MARCOS FRANCISCO MARTINS** \\ MARIA CARLA CORROCHANO*** \\ CAROLINA MOdENA DA SILVA****
}

\begin{abstract}
$2 \diamond$
RESUMO

Este artigo teve por objetivo assinalar o processo de institucionalização da Sociologia no ensino médio brasileiro, marcada pela intermitência entre obrigatoriedade, facultatividade e completa ausência da disciplina nas escolas. Para tanto se fez um rápido histórico da Sociologia no ensino médio, discutiu-se os desafios postos à área da Sociologia e das Ciências Sociais no que tange ao ensino da disciplina. Buscou-se, ainda, mapear a produção acadêmica acerca da Sociologia no ensino médio a partir das publicações de trabalhos apresentados nos Congressos da ANPOCS (Associação Nacional de Pesquisa e Pós-Graduação em Ciências Sociais), da ANPED (Associação Nacional de Pós-Graduação e Pesquisa em Educação) e da SBS (Sociedade Brasileira de Sociologia). Conclui-se que os desafios postos para o campo são inúmeros, dentre eles destacam-se: a discussão sobre os cursos de graduação e a relação entre bacharelado e licenciatura; a questão do currículo da disciplina; materiais didáticos; poucas horas aula no ensino médio e a necessidade de consolidação de uma área de pesquisa específica sobre ensino de sociologia não apenas em Programas de Educação, mas, sobretudo nos Programas de Sociologia e/ou Ciências Sociais.
\end{abstract}

Palavras-chave: Sociologia. Ensino de Sociologia. Ensino Médio.

\begin{abstract}
This article aims to point out the process of institutionalization of sociology in the Brazilian high school, marked by intermittence between compulsory, optionality and complete lack of the discipline in schools. That for it was made a quick history of sociology in high school and it was discussed the challenges faced by the field of sociology and social sciences in relation to the discipline teaching. It was attempted to map also the academic literature on the sociology in high school from the publications of papers presented in the Congress of the following associations: ANPOCS (National Association for Research and Graduate Studies in Social Sciences); ANPED (National Association of Graduate Studies and Research in Education) and SBS (Brazilian Society of Sociology). In conclusion, the challenges faced by the field are numerous, among them are: the discussion about the undergraduated courses and the relationship between bachelor's degrees and teacher training; the question about the course curriculum; teaching materials; few hours class in high school and the need to consolidate a specific area of research on the sociology of education not only in education programs, but especially in Sociology and/or Social Sciences programs.
\end{abstract}

Keywords: Sociology. Educational sociology. Sociology and High School.

* Doutora Ciências Sociais e estágio doutoral em Economia Civile pela Università Degli Studi di Milano-Bicocca. Professora Associada da Universidade Federal de São Carlos, Departamento de Ciências Humanas e Educação e da Pós-Graduação em Educação. E-mail: kelen@ufscar.br

**Professor Adjunto da UFSCar, Bolsista de Produtividade CNPq e Coordenador do Mestrado em Educação da UFSCar Campus Sorocaba. Docente do Departamento de Ciências Humanas e Educação e da Pós-Graduação em Educação.E-mail: marcosfranciscomartins@gmail.com

***Docente do Departamento de Ciências Humanas e Educação e da Pós-Graduação em Educação e do Programa de Pós-Graduação em Educação (PPGed-So) da Universidade Federal de São Carlos/Campus Sorocaba. Graduada em Ciências Sociais, Mestre e Doutora em Educação. E-mail carlacorrochano@gmail.com

****Licenciada e Bacharel em Ciências Sociais pela UNESP. Mestranda do Programa de Pós-Graduação em Educação da UFSCar. E-mail: carolmodena7@yahoo.com.br 


\section{RESUMEN}

Este artículo analiza el proceso de inclusión de la Sociología como asignatura en la enseñanza secundaria en Brasil. A través de un breve histórico son presentados los principales problemas y los desafíos de esta área de conocimiento en la enseñanza secundaria. Históricamente, dicha asignatura fue ofrecida de manera obligatoria u opcional, y en muchas ocasiones no hizo parte de la formación de los estudiantes. Mediante levantamiento bibliográfico en las actas de los congresos brasileños de la ANPOCS (Asociación Nacional de Investigación y Postgrado en Ciencias Sociales), de la ANPED (Asociación Nacional de Postgrado e Investigación en Educación) y de la SBS (Sociedad Brasileña de Sociología) se concluye que son muchos los problemas y los desafíos para la enseñanza de Sociología, destacándose sus especificidades, su relación con la formación del profesorado; la pertinencia de los currículos de secundaria; el uso de materiales didácticos; las muy pocas horas de clases de dicha asignatura en la enseñanza secundaria; y la necesidad de consolidación de un área de investigación específico sobre la enseñanza de la Sociología en los programas de maestría y doctorado en Sociología o Ciencias Sociales.

Palabras clave: Sociología. Enseñanza de Sociología. Sociología y Secundaria.

\section{INTRODUÇÃO}

Este artigo apresenta parte dos resultados da pesquisa intitulada Educação escolar de nivel médio e movimentos sociais: teoria e prática nas escolas públicas estaduais da região de Sorocaba/SP, financiado pelo Edital MCTI/ CNPq/CAPES n ${ }^{0}$ 22/2014 - Ciências Humanas e Sociais. A investigação em andamento tem por problemática central conhecer a abordagem que as escolas públicas estaduais de nível médio da região de Sorocaba/SP fazem sobre os movimentos sociais, particularmente por meio da disciplina de Sociologia quando ministrada na $3^{\mathrm{a}}$ série do ensino médio, momento em que se discute a questão dos movimentos sociais.

O grupo de pesquisadores é composto por docentes do Departamento de Ciências Humanas e Educação e do Programa de Pós-Graduação em Educação da Universidade Federal de São Carlos, bem como por discentes do Programa de Pós-Graduação. O trabalho de pesquisa se desenvolve em várias frentes e esse artigo tem por finalidade demarcar a questão da Sociologia no ensino médio, o que é basilar ao desenvolvimento do conjunto da investigação em curso. Isso é feito por meio de um levantamento, ainda que não exaustivo, da produção acadêmico-científica sobre essa temática na área da Sociologia, das Ciências Sociais e da Educação, e de um breve histórico da institucionalização da disciplina.

O referido levantamento identificou e analisou publicações online em Anais de três eventos organizados pelas seguintes sociedades científicas: ANPOCS (Associação Nacional de Pós-Graduação e Pesquisa em Ciências Sociais), ANPED (Associação Nacional de PósGraduação e Pesquisa em Educação) e SBS (Sociedade Brasileira de Sociologia).

Por sua vez, os apontamentos acerca da institucionalização da disciplina constituem-se como uma breve história sobre a presença/ausência da Sociologia no ensino escolar, destacando avanços e desafios a ela colocados com a aprovação da obrigatoriedade no ensino médio a partir do Parecer CNE/CEB 38/2006 e Lei no 11.684/2008. A definição desse marco legal, no entanto, não fez desaparecer a resistência à sua obrigatoriedade $\mathrm{e}$ às disputas em torno de seu lugar no currículo do Ensino Médio, o que também se articula ao próprio debate sobre os sentidos desse nível de ensino. De fato, em diferentes análises sobre o Ensino Médio, tanto no Brasil, quanto em diferentes países do mundo, ressalta-se a dificuldade de estabelecer consensos em torno de sua identidade e finalidades (formação geral e/ou formação para o mercado de trabalho) e em torno dos conteúdos que devem (ou não) ser incorporados no currículo da escola média (KRAWCZYK, 2014; SILVA, 2011). No conjunto desses embates, o questionamento sobre o lugar da disciplina de Sociologia sempre volta ao centro da cena. Não por acaso o recente Projeto de Lei (6.840/2013) apresentado à Câmara Federal novamente propôs a desobrigação da inclusão da disciplina no currículo. As severas críticas ao conjunto de propostas apresentadas ao PL levaram à constituição de um Movimento Nacional em Defesa do Ensino Médio, que conseguiu produzir alterações no projeto de lei, dentre as quais esta relativa à disciplina, mas a disputa ainda não chegou ao fim ${ }^{1}$. Neste momento

\footnotetext{
1 O PL 6840/2013 da Câmara dos Deputados propunha alterar a Lei no 9394, de 20 de dezembro de 1996, instituindo um conjunto de alterações no ensino médio, na contramão do que fora estabelecido pelas Diretrizes Curriculares Nacionais do Ensino Médio (2012). Para além da exclusão das disciplinas de Sociologia e Filosofia, como obrigatórias, propunha instituir a jornada em tempo integral no ensino médio, dispor sobre a organização dos currículos em áreas do conhecimento, em detrimento de uma base formativa mais sólida e a formação profissional desarticulada da formação acadêmica, dentre outras propostas que foram alvo de muitas críticas. As ações articuladas pelo Movimento Nacional em Defesa do Ensino Médio conseguiu barrar algumas dessas alterações, formulando um substitutivo que ainda não foi para votação em plenário, podendo, inclusive voltar ao debate dado o novo contexto político. RIBEIRO, M. Entrevista. In: <http://www.anped.org.br/news/entrevista-com-monicaribeiro-ufpr-conquistas-em-risco-ensino-medio $>$. Consultado em 26/5/2016.
} 
tem-se que a recém-aprovada Reforma do Ensino Médio², muito embora não desobrigue as escolas da oferta da Sociologia, permite que seus conteúdos sejam tratados apenas de modo transversal ou como objeto de estudo no interior de outras disciplinas específicas. Desse modo constituído, o presente texto pode ser de interesse a um público variado, particularmente aos que pesquisam sobre o ensino de Sociologia, aos que se dedicam à investigação sobre o ensino médio e mesmo à história da educação a partir desse recorte.

\section{BREVE HISTÓRICO DA SOCIOLOGIA NO ENSINO MÉdIO}

A história da presença da Sociologia como disciplina escolar é marcada pela intermitência entre obrigatoriedade, facultatividade e completa ausência. Percebe-se, todavia, que a discussão sobre o ensino de sociologia esteve na ordem do dia em alguns momentos da educação brasileira, porém não de modo perene, com pouca presença nos debates no campo da Educação, como evidencia a escassa discussão na ANPED e nos debates mais afetos a área das Ciências Sociais propriamente ditas, com a quase inexistente discussão na ANPOCS. Mais recentemente, é no interior da Sociedade Brasileira de Sociologia (SBS) que o debate parece ganhar mais força e relevância.

A presença da Sociologia em solo brasileiro remonta a iniciativas advindas de Rui Barbosa, que em 1882 propunha a entrada da disciplina nos cursos de Direito, formação de militares e, também, na escola secundária, nos seguintes termos: Elementos de Sociologia e Direito Constitucional, na escola secundária $e$, nas Faculdades de Direito, Sociologia ao invés do Direito Natural. Como positivista, as justificativas por ele apresentadas embasavam-se nos textos de Augusto Comte (MACHADO, 1987, p. 117).

É de se destacar que, segundo Rodrigues (2000), entre 1887 e 1902, Durkheim foi convidado para ministrar aulas de Pedagogia e Ciência Social na Faculté de Lettres de Bourdeaux, fundando em 1890, o primeiro Departamento de Sociologia na referida Universidade. O Brasil inicia as discussões em torno da disciplina de Sociologia em um momento em que ela ainda estava se estruturando e se demarcando como área de conhecimento no país de origem. Em 1902, Durkheim assumiu como assistente a cadeira de Ciência da Educação na Sorbonne,

\footnotetext{
2 Apresentada por meio da MP 746 e sancionada em 16/02/2017 pela Presidência da República implementa um conjunto de diretrizes para esse nível de ensino que vão na contramão das propostas construídas pelo Movimento Nacional em Defesa do Ensino Médio. Um conjunto de análises sobre esta Reforma pode ser acessado em <http://www.anped. org.br/news/reforma-do-ensino-medio-entenda-o-que-esta-em-jogo-evozes-desconsideradas-no-processo > . Acesso em 14/06/2017.
}

conseguindo transformá-la em cátedra de Sociologia em 1910, o que efetiva a entrada da Sociologia na academia pelas mãos do mestre. De maneira que, se comparada a outras ciências, pode-se dizer que a Sociologia é uma disciplina ainda jovem.

A proposta de Rui Barbosa, no entanto, não teve andamento interno no Parlamento, tendo sido, a Sociologia, introduzida como disciplina obrigatória nas escolas do Exército com o nome de Sociologia e Moral por meio da Reforma de Benjamim Constant, em 1890. Dessa vez, embora aprovada, não foi implementada e, com as mudanças de 1897, a disciplina desapareceu dos currículos do ensino ginasial e secundário (SILVA, 2010, p. 19-20).

Segundo Silva (2010), a Reforma de João Luís Alves-Rocha Vaz (1925-1942) incluiu a Sociologia como disciplina obrigatória para o ensino secundário e para as Escolas Normais, demarcando, desse modo, um momento fundamental para a institucionalização das Ciências Sociais/Sociologia que se dá, primeiro, pelo ensino secundário para, mais tarde, adentrar à Universidade que, em verdade, ainda era incipiente no país.

A partir de então a cronologia da disciplina é marcada pela intermitência no ensino médio. Em 1942, a Reforma Capanema retirou a Sociologia dos cursos secundários, deixando-a apenas nos cursos Normais. Em 1961, o País aprovou a primeira LDB (Lei de Diretrizes e Base), Lei n. 4.024/61, que manteve o ensino médio dividido entre ginasial e colegial e, em 1962, o Conselho Federal de Educação publicou os currículos para o ensino médio. Neles constava um conjunto de disciplinas obrigatórias e um sugestivo de disciplinas optativas, e a Sociologia passou a ser componente optativo do curso colegial, conjuntamente a uma dezena de outras disciplinas que possuíam o mesmo caráter (SILVA, 2010).

Entre 1971-1982, segundo Barbosa e Mendonça (2002), a disciplina passou a apresentar sempre maiores dificuldades de ser implementada, ainda que em caráter optativo, e isso se deveu, basicamente, ao fato de associarem a disciplina ao socialismo/comunismo e mesmo pela perda de criticidade na abordagem dada aos fatos políticos e/ou sociais pela introdução da disciplina obrigatória denominada OSPB (Organização Social e Política Brasileira).

Após essas idas e vindas há uma gradativa reinserção da Sociologia no ensino médio. A partir dos anos de 1980, associações e sindicatos mobilizaram-se pela volta da disciplina ao ensino básico no País. Gradativamente a Sociologia passou a ser reintroduzida em alguns estados como São Paulo, Pará, Rio Grande do Sul e Rio de Janeiro.

Com a LDB de 1996 (Lei 9394/96), os conhecimentos de Filosofia e Sociologia passaram a ser considerados fundamentais ao chamado exercício da cidadania, ainda 
que isso se constitua como algo genérico. No entanto, a interpretação da lei se deu do seguinte modo: "As propostas pedagógicas das escolas deverão assegurar tratamento interdisciplinar e contextualizado para conhecimentos de filosofia e sociologia necessários ao exercício da cidadania" (MORAES, 1999), o que possibilitou a interpretação de que não necessariamente deveria haver uma disciplina específica, mas o próprio governo federal, por meio dos APCNs, incluía a Sociologia.

Nesse transcurso, em 1999 os Parâmetros Curriculares para o Ensino Médio trouxeram "competências" relativas às áreas das Ciências Sociais, ou seja, Sociologia, Antropologia e Ciência Política. E dois anos depois, o sociólogo Presidente, Fernando Henrique Cardoso, vetou a Lei do Deputado Federal Padre Roque, do PT/PR, que tornava obrigatório o ensino de Sociologia e Filosofia em todas as escolas públicas e privadas. Em 2003,

[...] inicia-se uma nova equipe no MEC e nas secretarias de ensino médio e ensino profissionalizante (Governo Luiz Inácio Lula da Silva). Em 2004 formar-se uma equipe para rever os PCNEM. O MEC solicita às sociedades científicas a indicação de intelectuais ligados ao ensino para reformularem os PCNEM. Amaury Moraes e sua equipe inicia a elaboração das Orientações Curriculares para o Ensino Médio-Sociologia. Em 2005 Moraes elabora o Parecer que questiona as DCNEM e encaminha ao MEC que encaminha ao CNE. Cria-se o Grupo de Trabalho GT Ensino de Sociologia na Sociedade Brasileira de Sociologia e ocorrem duas sessões especiais sobre as questões do ensino no Congresso em Belo Horizonte. Em 2006 o CNE analisa o Parecer tornando a Filosofia e a Sociologia componentes ou disciplina obrigatória. Em 2007 vários estados questionam essa medida [...]. Em 2008 diante das resistências de alguns estados em acatar a mudança das DCNEM o Sindicato dos
Sociólogos de São Paulo liderou mais um movimento de pressão pela aprovação da Lei que obriga o ensino de Filosofia e Sociologia nas três séries do Ensino Médio, no Congresso e Senado. Em 02 de junho de 2008, o Presidente da República em exercício José de Alencar, assinou a lei 11.684. Em 2009 o CNE regulamenta o domo de implantação [...] ordenando sua efetivação até 2011 (SILVA, 2010, p. 42-45).

O Quadro 1, abaixo, busca sintetizar a obrigatoriedade, a facultatividade e a ausência da disciplina na educação básica desde a proposta de Rui Barbosa.

Partindo de Apple, Oliveira (2011, p. 5-7) afirma que:

[...] a presença ou ausência da sociologia, no currículo do ensino médio, representa demarcações de poder, que em boa parte do momento histórico, tem sido utilizado como estratégia de dominação e reprodução social. [...] E, [por sua vez, como será ressaltado mais à frente], o currículo, como espaço de tensão e expressão das relações de poder, numa dada sociedade (APPLE, 2006), faz transparecer tal dinâmica.

Essa breve caracterização, portanto, sobre a presença/ ausência do ensino de Sociologia nas escolas brasileiras demarca a intermitência e, em decorrência, uma série de outros aspectos e desafios, associados a outras variáveis, estão postos. Com a obrigatoriedade em 2008 , um conjunto de novos desafios se impõe não apenas para a disciplina de Sociologia no ensino médio, mas para o campo das Ciências Sociais no ensino superior. Tais desafios se relacionam com: a articulação entre o bacharelado e a licenciatura; a necessidade de consolidação de uma área de pesquisa em ensino de Sociologia; a legitimidade da disciplina; o currículo; os materiais didáticos; a carga horária da disciplina; além das condições de trabalho dos professores do ensino médio da rede pública.

Quadro 1. A presença da Sociologia na educação básica

\begin{tabular}{|l|c|c|c|}
\hline Períodos & Obrigatoriedade & Facultatividade & Ausência \\
\hline Proposta de Rui Barbosa/1882 & & & $\mathrm{X}$ \\
\hline Reforma Benjamim Constant/1890 & $\mathrm{X}$ & & \\
\hline Reforma João Luís Alves-Rocha Vaz/1925 & $\mathrm{X}$ & & $\mathrm{X}$ \\
\hline Reforma Capanema/1942 & & & $\mathrm{X}$ \\
\hline Conselho Federal de Educação/1962 & & $\mathrm{X}$ & \\
\hline Período Militar/1971 & & $\mathrm{X}$ & \\
\hline Associações e Sindicatos/1982 & & $\mathrm{X}$ & \\
\hline LDB 9394/1996 & & $\mathrm{X}$ & \\
\hline Parâmetros Curriculares para o Ensino Médio/1999 & $\mathrm{X}$ & $\mathrm{X}$ & \\
\hline Conselho Nacional de Educação/CEB - Parecer no 38/2006 & $\mathrm{X}$ & & \\
\hline Lei no 11.684/2008 & & & \\
\hline Efetivação/2011 & & & \\
\hline
\end{tabular}

Fonte: elaboração própria. 


\section{DESAFIOS POSTOS À ÁREA DE CiênCias Sociais E À Sociologia EM PARTICULAR}

A Sociologia, como em outros países, entrou no debate brasileiro pelo ensino básico, antes que houvesse um curso na área que só viriam a ser instituídos a partir dos anos de 1930, primeiramente na Escola Livre de Sociologia e Política de São Paulo e, posteriormente, na Universidade de São Paulo.

Ainda que no Brasil a entrada da Sociologia tenha se dado pelo ensino médio, a área, bem como outras, a exemplo de Filosofia, História, Geografia e Biologia, possui uma tensão estabelecida entre o bacharelado e a licenciatura, que se revela não tanto por objetos, métodos, metodologias e/ou teorias distintas, mas, sobretudo, pela hierarquização dos campos, como se o bacharelado fosse o primado da pesquisa e da densidade teórica e a área de ensino fosse algo menor, ligado exclusivamente à educação básica, à sala de aula e marcado por certa superficialidade.

Ademais, o Brasil foi marcado pela dualidade na educação escolar: a dos filhos dos trabalhadores e dos filhos das elites. Enquanto os primeiros dedicavam-se e, embora com mudanças significativas, ainda dediquem-se a cursos técnicos, à elite cabia o bacharelado, a formação integral de médicos e advogados, até hoje chamados de "doutores". Essa dualidade sempre esteve fortemente presente no Ensino Médio, lócus da disciplina de Sociologia.

Essa perspectiva não é exclusividade das Ciências Sociais, daí a necessidade em ser debatida, aprofundada e, possivelmente, superada. Faz-se necessário discutir profundamente o papel do bacharelado e da licenciatura, dos currículos, das relações com a pesquisa, o ensino e a extensão, pois será difícil consolidar uma área, ainda frágil na educação básica, se essa tensão não encontrar caminhos de superação. Para Moraes (2003, p. 01), a questão é

[...] fazer algumas passagens, algumas mudanças de ponto de vista: a primeira é que a formação do bacharelado não é suficiente, embora necessária para garantir ao professor as condições para o exercício das atividades de ensino - não basta saber o conteúdo; a segunda, é que se pode pensar na licenciatura, e não exclusivamente o bacharelado, também como um espaço de pesquisa. Isso, no entanto, importa numa revisão do currículo dos cursos de Ciências Sociais e a busca de um equilíbrio entre bacharelado e licenciatura; por exemplo, o que é realmente básico para a formação no bacharelado, ou na formação do sociólogo - pensando na profissão já regulamentada.

Segundo Handfas (2012), há uma discussão em torno da formação oferecida nos cursos de Ciências Sociais nas diferentes modalidades: o bacharelado e a licenciatura. A autora destaca a importância da formação na área das ciências da educação que a modalidade da licenciatura proporciona sem, contudo, romper com as disciplinas que formam a/o cientista social.

Da mesma forma, sob esse ângulo, é possível identificar aspectos positivos quando se trata de analisar os cursos de licenciatura com entrada independente do bacharelado, na medida em que a formação docente, parte constituinte das ciências da educação, guarda especificidades que devem necessariamente ser objeto de estudos concernentes a essas ciências, tais como a Didática, Psicologia, Filosofia, prática de ensino, educação brasileira, legislação, etc. Isso não significa priorizar essas disciplinas e preterir aquelas necessárias à formação do cientista social, mas, a depender de maneira de se estruturar o currículo, assim como da articulação dos professores dos departamentos de Ciências Sociais e de Didática, é possível que os cursos de licenciatura venham a reforçar o reconhecimento da especificidade da formação docente e, por conseguinte, incorporar conteúdos práticos e teóricos necessários para uma formação docente consistente e rigorosa (HANDFAS, 2012, p. 38).

No entanto, a perspectiva de entradas distintas e, portanto, formação distinta para o bacharelado e a licenciatura é tema de discussão e não de consenso.

$\mathrm{O}$ distanciamento entre bacharelado e licenciatura, entre formação do sociólogo e de professores de Sociologia para o ensino médio, relaciona-se, para além do já ressaltado, com o processo de institucionalização das Ciências Sociais como curso superior e a intermitência de sua presença no ensino médio. Tal distanciamento dificultou consolidar um campo de pesquisa em ensino de Ciências Sociais para a Educação Básica, o que foi ainda mais intenso a partir de 1960. A década de 1960/1970 é um período marcado pela criação e expansão das universidades públicas e pela política voltada à criação de Programas de Pós-Graduação, uma concepção coadunada com a perspectiva dos governos militares de promover a modernização do país.

Assim, o período em que a Sociologia esteve ausente do ensino médio (1971-1982) caracterizou-se justamente pelo crescimento das Universidades, da PósGraduação e, portanto, contribuiu para a consolidação e a institucionalização do campo das Ciências Sociais, ainda que isso não tenha se refletido na pesquisa em ensino de sociologia sendo um dos fatores a contribuir com isso a sua ausência no ensino médio, neste período específico e, também sua histórica intermitência.

Deste modo, tem-se que a constituição do campo passou a se dar no interior dos Programas de Pós-Graduação em Ciências Sociais sem que estes se preocupassem ou 
estabelecessem a educação e, mais especificamente, o ensino de ciências sociais e/ou sociologia como objeto de análise e campo a ser estruturado, consolidado e fortalecido.

As Ciências Sociais, desse modo, se afastaram das questões relativas ao ensino de Sociologia e da discussão sobre Sociologia da Educação, já que a área passou a concentrar-se mais em Programas de Educação e não em Ciências Sociais e/ou Sociologia. De fato, nota-se um claro afastamento em relação a uma tradição que havia sido fundamental na década de 1950 e no início dos anos 1960, sobretudo no pensamento sociológico paulista, que fortemente enraizado nas singularidades históricas, culturais, sociais e políticas do Brasil, havia trazido para o centro das reflexões sociológicas a educação e especialmente a escola, tanto como categoria analítica, quanto como categoria empírica (MARTINS, 1998; SPOSITO, 2003) .

Desse modo pouco a pouco os Programas de PósGraduação em Ciências Sociais foram se ausentando das discussões sobre o ensino de sociologia, reforçado pela não obrigatoriedade, e a pouca discussão restringiu-se à área da Educação, embora, como se verá mais à frente, os Anais da ANPED também apresentem pouco debate. A ANPOCS, pelos elementos apontados, praticamente não discutiu essas questões e a retomada dos debates foi feita pela SBS (Sociedade Brasileira de Sociologia).

Para Silva (et al., 2002)

[...] os intelectuais distanciaram-se dos debates sobre o ensino das ciências sociais em geral, e, em particular, no campo escolar [...] enquanto para os intelectuais das décadas de 1930 a 1960 a consolidação das ciências sociais no Brasil relacionava-se com a institucionalização nas escolas, para os intelectuais posteriores essa importância não estava dada. Tal hipótese vincula-se, evidentemente, aos trabalhos de Bourdieu sobre a hierarquia estabelecida entre os campos escolar e acadêmico-científico, de modo que o primeiro aparece como inferior ao segundo. Aliás, o autor ampliava sua crítica aos sociólogos que abandonaram o objeto educação para os pedagogos, abrindo até mão dessa especialidade - sociologia da educação - para os educadores.

Há, portanto, uma necessidade premente de se estruturar, consolidar e fortalecer uma área de pesquisa em Ensino de Sociologia nos Programas de Ciências

\footnotetext{
3 São expressivos nesse contexto os estudos pioneiros de Florestan Fernandes (1960), Fernando Henrique Cardoso e Octavio Ianni (1959) que, na análise das ambiguidades do processo de modernização no Brasil, reconheciam o lugar da educação escolar, os trabalhos de análise dos estudantes universitários nos processos de mudança social, de Marialice Foracchi (1965; 1972), os estudos de Celso Beisiegel (1974), ao analisar as articulações entre mudança social e mudança educacional, dentre outros (SPOSITO, 2003)
}

Sociais, a exemplo do que está fazendo a Universidade de Brasília (UNB), a Universidade Federal de Uberlândia (UFU), a Universidade Federal de Santa Maria (UFSM), a Universidade Federal de Goiás (UFG), a Universidade Federal do Rio Grande do Sul (UFRGS), a Universidade de São Paulo (USP), a Universidade Estadual de Londrina (UEL).

Vários autores, dentre eles Sarandy (2011), ressaltam que não há garantias que a obrigatoriedade do ensino de sociologia se mantenha, pois é preciso construir e garantir a legitimidade da disciplina no ensino médio. Tanto isso se coloca deste modo que, recentemente, quando da discussão sobre a proposta de reforma do ensino médio, apresentada pelo governo instituído pelo parlamento brasileiro em 2016, este propôs, novamente, que a sociologia fosse retirada do currículo como disciplina obrigatória.

Há, ainda, outras questões importantes como demostra Pimenta (2013, p. 2018) ao afirmar que o ensino de Sociologia encontra-se marcado por duas lógicas distintas:

[...] ou o ensino é marcado por um resumo abreviado das matrizes curriculares das graduações dos cursos de Ciências Sociais; ou lista de temas contemporâneos violência, bullying, racismo, sexualidade, relações de gênero, redes sociais, culturas juvenis, etc.

Neste debate pesquisadores se posicionam a partir de ambas as perspectivas. Santos (2014) irá afirmar que

[...] essas duas tendências reproduzem as matrizes curriculares da graduação. Alguns estudos apontam que elementos dessas matrizes constituem o referencial comum dos livros didáticos (SARANDY, 2001), das diretrizes curriculares estaduais (SANTOS, 2012) e dos programas de vestibulares (MATIOLLI; FRAGA, 2014). Em contraposição a essa concepção, um grupo minoritário de docentes concebe os temas e as problemáticas que emergem espontaneamente do cotidiano estudantil devem constituir os conteúdos do conhecimento escolar. Por conseguinte, procuram desenvolver atividades pedagógicas nas quais o centro do processo não seja o professor, mas o aluno.

\section{Por sua vez, para Dias (2012, p. 57)}

É sabido que a mera transposição para o Ensino Médio das aulas nos moldes em que são oferecidas nas faculdades e universidades é ineficaz. Portanto, faz-se necessário desenvolver metodologias e práticas que visem traduzir o conteúdo das Ciências Sociais e da Filosofia tal como aprendidos e ensinados no Ensino Superior para o contexto escolar.

Desse modo, o que ocorre, via de regra, no ensino de Sociologia, é a manifestação de duas tendências. 
Uma na qual os professores organizam suas atividades baseados na transmissão dos conceitos como: classes, interação social, cultura, estratificação social, mobilidade social, movimentos sociais, questões de gênero, feminismo, questões étnico-raciais dentre outras. E outra preocupada em transmitir os fundamentos das principais correntes teóricas: a sociologia funcionalista, marxista e compreensiva (SANTOS, 2014, p. 63). Há um intenso debate na área em relação a essas questões e sobre a necessidade ou não de um currículo unificado para a disciplina, tal debate poderia avançar se aprofundar e tornar-se mais propositivo com uma área específica dedicada ao ensino de Sociologia nos Programas de Pós-Graduação em Sociologia e/ou Ciências Sociais e não apenas relegar tais discussões, essencialmente, aos Programas de Educação.

Contribuindo para a discussão acerca da concepção da Sociologia na escola básica, Ferreira e Carneiro (2012, p. 195) ressaltam que

[...] a inevitável convivência com os pressupostos e impressões pessoais de nossos alunos acerca da realidade social é um dos grandes desafios enfrentados por professores de Sociologia na escola básica. O envolvimento com os temas sociais na vida cotidiana produz nos alunos certa naturalidade e alguma resistência em deslocarem-se de seus lugares de percepção e descobrirem novas leituras do cotidiano, principalmente o olhar sociológico.

Outra questão levantada, mas que não é um problema específico da área da sociologia, diz respeito aos desafios inerentes à própria expansão do ensino médio no País é que além das questões relativas à sua identidade formação geral e/ou profissional - já tratada por um significativo conjunto de estudos (KRAWCZYK, 2014), há um relativo consenso na literatura de que a expansão da oferta pública e gratuita desse nível de ensino no Brasil se realizou a partir de um regime precário, sem que fossem realizados investimentos necessários para a incorporação dessa ampla e heterogênea população, outrora alijada da educação básica. Se esse regime permitiu o acesso de diferentes camadas da população à escola, a insuficiência de recursos materiais e humanos para acolhê-la produziu uma escola pública degradada em suas condições de organização e funcionamento. Como consequência essa escola que abriga, sobretudo os jovens de famílias pobres, tem se caracterizado como espaço de improvisação no qual professores trabalham com regime de contratação precária, em lugares sem bibliotecas, laboratórios, computadores, ginásios ou auditórios com funcionários em número insuficiente (BEISIEGEL, 2006; DAYRELL, 2007). Recentemente, em diferentes estados do País, assiste-se a uma intensificação da precarização das condições de trabalho dos docentes por meio das propostas de passagem da gestão das escolas públicas para OS's (Organizações Sociais) - já concretizada em Goiás - e em disputa nos estados de São Paulo e Rio de Janeiro, por exemplo. De fato, há um conjunto de propostas de reorganização das escolas em todo o território nacional que está longe de significar a expansão do acesso e a melhoria da qualidade. Por isso mesmo, várias dessas propostas têm enfrentado significativos movimentos de resistência, como as ocupações protagonizadas por estudantes secundaristas, que têm contado com importante apoio de docentes e da comunidade em geral.

Problemas para a consolidação do campo dizem respeito, também, à questão do currículo e dos materiais didáticos. Segundo Moraes (2003), desde pelos menos 1986 tem-se produzido propostas de programas e matérias didáticos, mais extensos ou não (cf. Dossiê Ceupes/ CACS, 1985; Cenp, 1986 e 1992; PCN, 1999); livros didáticos também foram produzidos entre enciclopédicos, temáticos ou de história da sociologia. Para Moraes (2003) seria necessário, para a consolidação dos conteúdos programáticos e materiais didáticos, o reconhecimento de uma área de pesquisa em Ensino de Sociologia, bem como a superação do modelo atual e a proposta de uma efetiva integração entre o bacharelado e a licenciatura. $\mathrm{O}$ bacharelado e a licenciatura pensados e executados de forma estanque produzem uma formação dissociada do professor.

A proposta de integração vinda de Moraes (2003) aponta para a necessidade de avançar em direção a uma reforma da licenciatura que tivesse profundidade e radicalidade, integrando três áreas de conhecimentos (teóricos e práticos) necessários para a formação do professor da educação básica:

1. Conhecimentos específicos: no caso das ciências sociais, sociologia, antropologia, ciência política, metodologia da pesquisa, obrigatórias e optativas, gerais e especiais.

2. Conhecimentos pedagógicos: formação em disciplinas que tomam o fenômeno educacional e escolar como objeto, psicologia, história, filosofia, sociologia da educação e políticas educacionais e gestão escolar.

3. Conhecimentos metodológicos e epistemológicos sobre o ensino: conjunto de disciplinas de integração entre (1) e (2) que tratam de conteúdos, didáticas e pesquisas sobre o ensino de ciências sociais para a educação básica (MORAES, 2003, p. 45).

Handfas, em estudos posteriores (2012, p. 29), considera importante compreender como ocorre a formação da (o) professora(o) na licenciatura e discute como problemática a dicotomia entre a teoria e a prática presente nessa modalidade de curso, em certo sentido as 
preocupações postas por Moraes (2003) permanecem presentes.

Esses estudos indicam que durante um longo tempo a formação do professor foi realizada a partir de dois momentos distintos e independentes: o momento da teoria, onde os conteúdos das disciplinas didáticopedagógicas eram transmitidos e o momento da prática, quando o professor deveria ir a campo praticar aquilo que foi aprendido. Nessa perspectiva, a teoria e a prática estabeleciam uma relação de justaposição, sem considerar que o conhecimento depende da prática que é sempre uma prática social.

Como se percebe, a Sociologia precisa enfrentar os debates que abarcam sua atuação na educação básica e os conflitos existentes em relação à formação docente.

\section{ProduÇão ACADÊMicA ACERCA da SOCIOLOGIA NO ENSINO MÉDIO EM ANAIS DE EVENTOS}

Um dos objetivos deste artigo foi realizar um breve levantamento da produção acadêmica acerca da temática nos últimos anos, por meio das publicações disponibilizadas online em três grandes eventos organizados por associações científicas da área, a saber: ANPOCS, no site os eventos disponibilizados retroagem de 1977 a 2014; ANPED, nos eventos entre os anos de 2000 a 2014 e, por fim, SBS, entre 1954 a 2013. Esse foi o recorte temporal empregado no levantamento realizado nos Anais, pois era o material disponibilizado nos portais, cujos textos foram identificados por meio da busca de GT por GT, no momento da pesquisa, maio de 2016.

A ANPOCS realiza encontros anuais desde 1977. Somente em 1987, no 11ํㅡㄹ Encontro, foi criado um GT (Grupo de Trabalho) sobre Educação. O GT 25 - Educação e Sociedade, no entanto, não abarcava discussões sobre o ensino de Sociologia no ensino médio. Em 1988 e 1989 o GT continua presente no evento, mas o debate sobre o ensino não se apresentava nas reuniões anuais. Em 1990 o referido GT não esteve presente no encontro, mas a ele retornou em 1991 e 1992 sem, contudo, tomar a temática sobre o ensino de Sociologia no ensino médio como objeto das discussões, tanto que ela não aparece nos Anais disponibilizados. Todavia, em 1993, mesmo com o GT novamente ausente, a educação foi discutida na Sessão Temática (ST) "Estado, Sociedade e Educação". No ano seguinte, o debate sobre educação ocorreu novamente no GT Educação e Sociedade, momento em que se focou a questão do professor. Em 1995 o GT se manteve no Encontro, entretanto, sem discutir sobre o ensino de Sociologia no ensino médio.

Até o Encontro de 1995 apenas alguns trabalhos eram disponibilizados no site dos eventos. Isso mudou a partir de 1996, quando o site passou a conter os arquivos de todos os trabalhos apresentados no evento. Nesse ano o GT Educação e Sociedade também não abordou a temática aqui em análise. No 21ํㅡㄹ Encontro, em 1997, a única ST que abordou o tema educação focou a questão indígena. Em 1998, o GT não abordou o ensino de sociologia no ensino médio e no ano seguinte o GT não foi realizado, reaparecendo em 2000, porém, sem levantar a discussão sobre o ensino. Em 2001 novamente o GT sobre educação não aparece. Nos anos de 2002 e 2003 o GT Educação e Sociedade não abordou a temática do ensino de Sociologia no ensino médio. Em 2004, no 28을 Encontro, o GT não foi realizado, e em 2005 e 2006 o GT Educação e Sociedade ocorreu sem abarcar a temática deste artigo. Em 2007 a discussão sobre educação foi centrada no ST: "Sociedade brasileira e educação: o que já sabemos? O que precisamos saber?". Contudo, a discussão sobre o ensino de Sociologia não ocorreu. Essa discussão não foi abordada pelo GT Educação e Sociedade em 2008 e 2009, e em 2010 sequer ocorreu a ST sobre Educação, fato que retrata a pouca incidência da educação nas pesquisas da área de Ciências Sociais.

Em 2011, no 35 Encontro Anual da ANPOCS, a discussão sobre a educação foi realizada pelo GT Educação e Sociedade e o trabalho de Roberta dos Reis Neuhold, intitulado: "As contribuições do campo acadêmicocientífico aos debates sobre a institucionalização da Sociologia na educação básica", abordou a temática aqui em análise. No ano de 2012, realizou-se o GT, mas não se discutiu sobre o ensino de Sociologia no ensino médio. Em 2013 o GT sobre educação não foi realizado. No $38^{\circ}$ Encontro, em 2014, a discussão sobre a educação ocorreu na SPG - "Ciências Sociais e educação: dilemas e possibilidades na produção do conhecimento" e o trabalho intitulado "Ensino de Sociologia e Políticas Públicas Educacionais: funções e percursos na Educação Básica”, de Bruna Muniz da Silva, contemplou a temática.

Por meio desses levantamentos percebe-se que, no âmbito da Associação Nacional de Pós-Graduação e Pesquisa em Ciências Sociais, as questões relacionadas ao ensino de Sociologia no ensino médio não estão postas de forma constante, demarcando o fato que o ensino de Sociologia parece não estar na agenda dos pesquisadores e dos debates dessa importante Associação no âmbito da Sociologia e das Ciências Sociais. Tal constatação se deve às questões já mencionadas neste artigo, bem como a outras que mereceriam maior aprofundamento em outras pesquisas.

Em relação à ANPED, a discussão sobre a Sociologia no ensino médio ocorreu de maneira descentralizada, nos GTs Sociologia da Educação, Educação de Pessoas Jovens e Adultas, Trabalho e Educação e Formação de Professores. No entanto, o 
número de trabalhos apresentados sobre esta temática também é pequeno como na ANPOCS.

A 1a Reunião Científica da ANPED ocorreu em 1978, na Universidade Federal do Ceará (UFC), em Fortaleza/CE. Ao longo dos anos as reuniões se tornaram anuais e já foram realizados trinta e sete encontros com o intuito de apresentar a discussão realizada na área da Educação. A partir da $23^{\text {a }}$ Reunião Anual da ANPED, no ano 2000, em Caxambú/MG, os Anais dos eventos foram disponibilizados na internet, fonte que a pesquisa aqui relatada consultou.

No ano de 2000 a discussão sobre o ensino de Sociologia foi realizada com o trabalho intitulado: "A Sociologia na formação dos professores catarinenses", produzido por Maria das Dores Daros, Carla D'Lourdes do Nascimento e Leziany Silveira Daniel, da Universidade Federal de Santa Catarina (UFSC) no GT Sociologia da Educação. Na 26ª Reunião Anual, em 2003, no GT Educação de Pessoas Jovens e Adultas, o trabalho Kelly Cristine Corrêa da Silva discutiu o ensino de Sociologia no ensino médio: "Os lugares da Sociologia na formação escolar de estudantes do ensino médio: a perspectiva de professores". A 30a Reunião, de 2007, e contou com a apresentação do trabalho "A categoria trabalho nos textos didáticos utilizados para o ensino de Sociologia no Ensino Médio", de Marival Coan e Paulo Sergio Tumulo, no GT Trabalho e Educação. Em 2015, na 37ª Reunião Anual, o ensino de Sociologia foi discutido no trabalho de Paulo Pires de Queiroz intitulado "A formação do professor de Sociologia da escola básica: problematizando algumas questões a partir da pesquisa e prática de ensino de Ciências Sociais", apresentado no GT Formação de Professores.

Demarca-se, portanto, que embora a discussão da educação e, especificamente, do ensino de Sociologia estejam quase ausentes da ANPOCS, uma vez que tais questões são mais discutidas em Programas de PósGraduação em Educação, elas também não aparecem com força na ANPED.

Por sua vez, no I Congresso Brasileiro de Sociologia (CBS), realizado em 1954, o Ensino de Sociologia foi o destaque do evento. As três comunicações realizadas naquela ocasião, que constam no site da SBS, abordam esse tema: a discussão de Florestan Fernandes intitulada: "O ensino de Sociologia na Escola Secundária brasileira", a apresentação de Antonio Candido sobre: "O papel do estudo sociológico da escola na Sociologia Educacional”, e o trabalho de Oracy Nogueira intitulado: "Duas experiências no ensino da Sociologia". Importa destacar que a pesquisa realizada consultou os Anais dos eventos (http://www.sbsociologia.com.br/home/home.php).

Em dois eventos posteriores, presentes no site, um do ano de 1987 e outro de 1989, ou seja, o III e o IV
Congresso Brasileiro de Sociologia, a discussão sobre o Ensino de Sociologia no ensino médio não foi realizada. Em 2003 foi realizada a XI edição do referido Congresso e nela há um GT "Educação e Sociedade" tratando das questões relacionadas ao ensino, porém somente no nível superior. Por sua vez, no GT "Participação Social e Cidadania", o trabalho de Virgínia Villas Boas Sá Rego, intitulado: "Construindo Sujeitos: o Ensino de Sociologia e a Formação do Cidadão no Século XXI" abordou a discussão sobre o ensino de Sociologia no nível médio e a importância na formação dos jovens brasileiros.

No XII Congresso Brasileiro de Sociologia, realizado em 2005, a discussão sobre o ensino de Sociologia no nível médio não apareceu no GT "Educação e Sociedade", pois foi criado um GT específico sobre o ensino intitulado: "Experiências de Ensino em Sociologia: Metodologia e Materiais Didáticos", com cinco trabalhos abordando a temática proposta. No XIII Congresso Brasileiro de Sociologia, de 2007, o GT "Educação e Sociedade" não contemplou a discussão que aqui se pesquisa, já que o GT "Ensino de Sociologia" centralizou esse debate, com onze trabalhos selecionados para a discussão desta temática. Em 2009 ocorreu o XIV Congresso e a discussão do ensino foi centrada no GT Ensino de Sociologia, onde treze trabalhos foram selecionados sobre a temática. No XV Congresso, de 2011, o GT Ensino de Sociologia contemplou a discussão proposta com quinze trabalhos selecionados. No Congresso de 2013, o XVI, a discussão sobre o ensino de Sociologia no nível médio ocorreu em dois GTs que abarcavam algumas Sessões Temáticas (ST). Houve uma sessão: "Formação de professores em ciências sociais: experiências, cursos e programas". Outra sessão foi intitulada: "Institucionalização da disciplina escolar; história, condições e situação". Terceira sessão: "Pesquisas, teorias, problematização da história/escolas e percepções de diferentes agentes sobre a inserção da sociologia nas escolas". Assim, vinte e cinco trabalhos que foram apresentados no Congresso discutiram a questão do ensino de Sociologia no ensino médio.

Analisando o Gráfico 1, adiante, é possível perceber que a discussão sobre o ensino de Sociologia cresceu ao longo do tempo na Sociedade Brasileira de Sociologia, que também esteve à frente, com outros sujeitos, na reivindicação da obrigatoriedade da disciplina no ensino médio.

Esses dados indicam que, em relação ao ensino de Sociologia, quem organiza e induz as discussões tem sido a entidade SBS, fundada em 1937 como Sociedade Paulista de Sociologia, passando, em 1950, a denominar-se pelo nome atual e a reunir pesquisadores da área em todo território nacional, com regularidade nos congressos bianuais a partir de 1987 . 
Gráfico 1. O ensino de Sociologia na educação básica na SBS

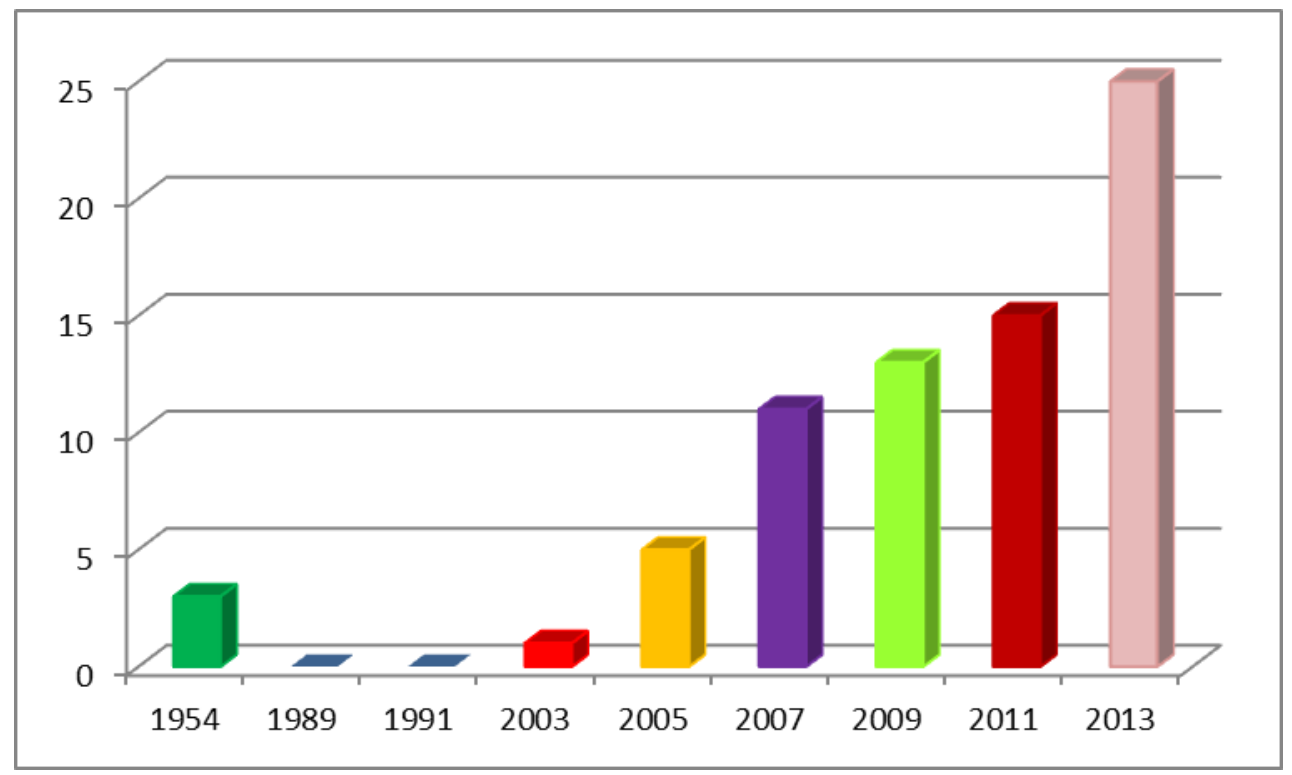

Fonte: elaboração própria a partir dos Anais da SBS.

A SBS declara ter por objetivo: "estimular o ensino e a pesquisa em Sociologia e desenvolver iniciativas voltadas ao desenvolvimento das ciências humanas e sociais no país"4. Tal discussão, fortemente fomentada pela SBS, encontra-se praticamente ausente dos debates centrados na área da Educação que, por outro lado, focou ao longo dos anos a discussão sobre ensino e as discussões sobre a Sociologia da Educação, por meio da ANPED. $\mathrm{Na}$ ANPOCS tal debate encontra-se ausente também. O quadro seguinte apresenta uma síntese desses dados.

Quadro 2. temática dos trabalhos encontrados no Anais dos eventos

\begin{tabular}{|l|c|c|c|}
\hline Temáticas & ANPED & ANPOCS & SBS \\
\hline Ensino de Sociologia & 1 & & 27 \\
\hline Formação de professores & 2 & & 5 \\
\hline Institucionalização da Sociologia & & 1 & 14 \\
\hline Material didático & 1 & & 3 \\
\hline Metodologia & & & 13 \\
\hline Trabalho docente & & 1 & 11 \\
\hline Total & 4 & 2 & 73 \\
\hline
\end{tabular}

Fonte: elaboração própria a partir dos Anais da ANPED, ANPOCS e SBS disponibilizados nos respectivos sites.

$\mathrm{O}$ rico material encontrado nesses 79 trabalhos evidencia a necessidade de uma nova pesquisa, a ser realizada, debruçando-se sobre o conteúdo desse material,

\footnotetext{
${ }^{4}$ Disponível em: $<$ http://www.sbsociologia.com.br/home/index.php?form ulario $=$ asociedade $\&$ metodo $=0 \& i d=1>$. Acessado em: 16 fev. 2016 .
}

sobretudo uma análise que pudesse perceber e aprofundar as temáticas, os problemas de pesquisa, a frequência de assuntos bem como a originalidades das abordagens presentes.

No entanto, é mister destacar, a partir do quadro acima apresentado, que a temática sobre o ensino de Sociologia é a mais debatida nos eventos, com total de vinte oito trabalhos selecionados, sendo vinte e sete deles concentrados na SBS. As preocupações aqui apresentadas pelas e pelos autores trazem à tona questões relacionadas à própria formação docente. Dificuldades apresentas e constatadas pelas pesquisas apontam a ausência, muitas vezes, de licenciados em ciências sociais atuando na área, dentre os licenciados na área sobressai o discurso da hierarquização entre o bacharelado e a licenciatura e a quase inexistência, nos cursos de ciências sociais, de aprofundamentos em metodologias de ensino em sociologia. Nas pesquisas com entrevistas aos docentes do ensino médio, invariavelmente, essas questões são por eles levantadas. A discussão sobre a institucionalização da disciplina na educação básica abarca quinze trabalhos. As preocupações apresentadas dizem respeito ao modo como a Sociologia se instituiu no Brasil e marca a discussão sobre a sua intermitência no ensino médio, demonstrando o quanto esse fato contribuiu para que não tivéssemos, ainda, uma área de pesquisa forte e consolidada sobre em ensino de sociologia. A discussão sobre a metodologia do ensino de Sociologia abarca treze trabalhos, todos apresentados nos eventos da SBS e se preocupam, basicamente, em como desenvolver estratégias para que o conteúdo da disciplina que, muitas vezes, pode 
apresentar-se árido, consiga ser eficazmente trabalhado em sala de aula. Outra temática bastante abordada envolve o trabalho docente, com doze trabalhos apresentados, neste campo, embora possa haver especificidades ligadas à sociologia, as questões, basicamente, giram em torno das condições de trabalho, da intensificação do trabalho, da carga horária, da necessidade de estar em várias escolas, dentre outras variáveis que contribuem para a precarização do trabalho do docente de sociologia. A discussão sobre a formação de professores, com sete artigos, sendo dois deles apresentados na ANPED revelam a necessidade de se repensar a formação de professores de ciências sociais e/ou sociologia. A hierarquização do bacharelado e licenciatura, sua profunda separação e a falta dessas discussões no interior dos departamentos de ciências sociais e/ou sociologia, bem como a falta de estabelecimento de uma área fortemente consolidada em ensino de sociologia nos Programas de Pós-Graduação em Sociologia, a exemplos de outras áreas como a Geografia, fragilizam a formação deste profissional. Por fim, o material didático da disciplina foi abordado por quatro trabalhos ao longo dos anos e a discussão gira em torno da avaliação dos materiais produzidos.

Assim compilados os dados, torna-se evidente que a discussão sobre a Sociologia na educação básica está ocorrendo principalmente na SBS. Os trabalhos de pesquisa e grupos de estudos tendem a aumentar ao longo dos anos, já que ainda são necessárias novas abordagens e debates sobre essa área de ensino e pesquisa.

\section{CONSIDERAÇÕES FINAIS}

Há que se destacar que a Sociologia no ensino básico e/ou no ensino médio no Brasil foi marcada pela intermitência entre obrigatoriedade, facultatividade e completa ausência. Dentre outras questões, esse fato contribuiu para que no momento de consolidação dos Programas de Pós-Graduação no País a discussão não estivesse presente nos Programas de Ciências Sociais e/ou Sociologia.

Soma-se a essa questão a relação conflituosa que se estabeleceu entre bacharelado e licenciatura, bem como o deslocamento da Sociologia da Educação para os Programas ligados à Educação e não às Ciências Sociais.

Os desafios postos para o campo são inúmeros, dentre eles destacam-se: a discussão sobre os cursos de graduação e a relação entre bacharelado e licenciatura; a questão do currículo da disciplina; materiais didáticos; poucas horas aula no ensino médio e a necessidade de consolidação de uma área de pesquisa específica sobre ensino de Sociologia, entendendo que seria relevante que este campo de pesquisa estendesse e fosse consolidado nos Programas de Sociologia e/ou Ciências Sociais, o que está sendo feito por alguns Programas.
Em tempos de discussão inconstitucional de "escola sem partido", é preciso reafirmar a legitimidade da Sociologia no ensino médio e sua relevância para a compreensão dos fenômenos sociais, bem como para a leitura crítica da realidade social, política, cultural e econômica da contemporaneidade.

\section{REFERÊNCIAS}

BEISIEGEL, Celso de Rui. Ação política e expansão da rede escolar. São Paulo: CRPE, Pesquisa e Planejamento, 1964.

BEISIEGEL, Celso de Rui. Estado e educação popular. São Paulo: Pioneira, 1974.

BEISIEGEL, Celso de Rui. Relações entre a quantidade e a qualidade do ensino comum. A qualidade do ensino na escola pública. Brasília: Líber, 2006.

CARDOSO, Fernando Henrique; IANNI, Otavio. As Exigências Educacionais do Processo de Industrialização. Revista Brasiliense, São Paulo, v. 26, 1959.

DAYRELL, Juarez Tarcisio. A escola "faz" as juventudes? Reflexões em torno da socialização juvenil. Educação e Sociedade, Campinas, v. 28, n. 100, p. 1105-1128, out. 2007.

DIAS, Viviane Gonçalves. Pesquisa e ensino de sociologia no ensino médio: desafios e possibilidades. In: HANDFAS, Anita; POLESSA, Maçaira Julia (Org.). Dilemas e perspectivas da Sociologia na Educação Básica. Rio de Janeiro: e-papers, 2012.

FERNANDES, Florestan. Ensaios de Sociologia Geral e Aplicada. São Paulo, Pioneira, 1960.

FERREIRA, Fátima de Oliveira; CARNEIRO, Silzane de Almeida. Nem tudo que é social é sociológico: sociologia e senso comum na escola básica. In: HANDFAS, Anita; POLESSA, Maçaira Julia (Org.). Dilemas e perspectivas da Sociologia na Educação Básica. Rio de Janeiro: e-papers, 2012.

FORACCHI, Marialice. O estudante e a transformação da sociedade brasileira. São Paulo, Nacional, 1965.

FORACCHI, Marialice. A juventude na sociedade moderna. São Paulo: Pioneira, 1972.

HANDFAS, Anita. Formação dos professores de Sociologia: um debate em aberto. Dilemas e perspectivas da Sociologia na Educação Básica. Rio de Janeiro: e-papers, 2012.

HANDFAS, Anita. A Sociologia no ensino médio: experiências em Santa Catarina. Anais do XII Congresso Brasileiro de Sociologia, realizado em Belo Horizonte-MG, de 31 de maio a 03 de junho de 2005.

JOSEFA, Alexandrina Silva. Sociologia no Ensino Médio no Estado de São Paulo: entre o proposto e o apropriado. Anais do XV Congresso Brasileiro de Sociologia, realizado em Curitiba-PR, de 26 a 29 de julho de 2011.

KRAWCZYK, Nora. Conhecimento crítico e política educacional: um diálogo difícil, mas necessário. In: KRAWCZYK, Nora (Org.). Sociologia do ensino médio: crítica ao economicismo na política educacional. São Paulo: Cortez, 2014.

MACHADO, Celso de Souza. O Ensino da Sociologia na escola secundária brasileira: levantamento preliminar. Revista da Faculdade de Educação, São Paulo, v. 13, n. 1, p. 115-142, 1987. 
MARTINS, José de Souza. Florestan. Sociologia e consciência social no Brasil. São Paulo: Edusp/Fapesp, 1998.

MORAES, Amaury César. Licenciatura em Ciências Sociais e Sociologia. Tempo Social, São Paulo, v. 15, n. 1, p. 5-20, maio 2003.

MORAES, Amaury César. Parecer sobre o ensino de Filosofia e de Sociologia. Mediações, Revista de Ciências Sociais do Programa de Pós-Graduação da Universidade Estadual de Londrina, Londrina, v. 12, n. 1, jan./jun. 2007. Dossiê Ensino de Sociologia. Disponível em: <http://www2.uel.br/revistas/ mediacoes/mediacoes_v12n1_2007.html $>$. Acesso em: 25 fev. 2016.

MORAES, Amaury César. Ciência e ideologia na prática dos professores de Sociologia no Ensino Médio: da neutralidade impossível ao engajamento indesejável, ou seria o inverso? Educação \& Realidade, Porto Alegre, v. 39, n. 1, p. 17-38, jan./mar. 2014. Disponível em: <http://seer.ufrgs.br/index.php/ educacaoerealidade/article/view/37585>. Acesso em: $27 \mathrm{dez}$. 2015.

OLIVEIRA, Amurabi. Ensino de Sociologia, Estado Nacional e reflexividade: formação de um campo. Anais do XV Congresso da Sociedade Brasileira de Sociologia, Curitiba, julho 2011.

PEREIRA, Luiza Helena. Qualificando Futuros Professores de Sociologia. Mediações, Londrina, v. 12, n. 1, p. 143-158, jan/ jun. 2007.

PIMENTA, Rosangela Duarte. Ensino e pesquisa: do pedágio ao trânsito livre. In: RAMALHO, José Rodorval; SOUZA, Rozenval de Almeida (Org.). PIBID: memórias de iniciação à docência. Campina Grande: Editora UFCG, 2013.

RODRIGUES, José Albertino. Durkheim. São Paulo: Ática 1995. (Col. Grandes Cientistas Sociais).
SANTOS, Mário Bispo. O PIBID na área de Ciências Sociais: condições epistemológicas e perspectivas sociológicas. Revista Brasileira de Sociologia, São Paulo, v. 2, n. 3, jan./jun. 2014.

SARANDY, Flávio Marcos Silva. Reflexões acerca do sentido da Sociologia no Ensino Médio: desenvolver a perspectiva sociológica: objetivo fundamental da disciplina no Ensino Médio. Revista Espaço Acadêmico, v. 5, out. 2001. Disponível em <http://www.espacoacademico.com.br/005/05sofia.htm. Acesso em 29/07/2016>

SARANDY, Flávio Marcos Silva. O ensino de sociologia na escola média brasileira e as apropriações simbólicas da disciplina. Anais do XV Congresso Brasileiro de Sociologia, realizado em Curitiba-PR, 26 a 29 julho 2011.

SILVA, Ileizi Fiorelli. A Sociologia no Ensino Médio: os desafios institucionais e epistemológicos para a consolidação da disciplina. Anais do XII Congresso Brasileiro de Sociologia - SBS, Belo Horizonte, MG, 2005.

SILVA, Ileizi Fiorelli. O Ensino das Ciências Sociais/ Sociologia no Brasil: histórico e perspectivas. MEC, Brasília, 2010. (Col. Explorando o Ensino - Sociologia. Cood. Amaury César Moraes).

SILVA, Ileizi Fiorelli et al. O ensino de ciências sociais: mapeamento do debate em periódicos das ciências sociais e da educação de 1940-2001. Anais do XII Congresso Nacional de Sociólogos. Curitiba, 1 a 4 abril 2002.

SPOSITO, Marilia Pontes. Uma perspectiva não escolar no estudo sociológico da escola. Revista USP, São Paulo, n. 57, p. 210-226, mar.-maio, 2003.

Recebido em 06-01-2017

Aprovado em 31-10-2017. 